\title{
PENGARUH AKUNTANSI PERTANGGUNGJAWABAN TERHADAP PENGENDALIAN MANAJEMEN PADA PT. HAGANAMO MANDIRI
}

\author{
Nitema Gulo $^{1}$, Po Abas Sunarya ${ }^{2}$, Milani $^{3}$ \\ ${ }^{123}$ Dosen Fakultas Ekonomi dan Bisnis Universitas Raharja \\ nitema@raharja.info
}

\begin{abstract}
Abstrak
Akuntansi merupakan suatu kegiatan yang sangat penting dalam mengidentifikasi, melaporkan, dan menyediakan suatu informasi untuk melaporkan dan penilaian bagi pihak terkait sehingga dapat mengambil sebuah tindakan. Manajemen adalah sebuah proses dan kemampuan untuk mengatur suatu kegiatan sekaligus pengendalian sehingga tercapai target yang telah ditentukan. Suatu perusahaan yang baik dapat menerapkan sistem akuntansi dan manajemen sesuai dengan kebutuhan perusahaan. akuntansi pertanggungjawaban sangat penting dalam suatu perusahaan karena semua kegiatan yang telah terjadi akan dipertanggungjawabkan kepada pihak yang berkepentingan. Sedangkan pengendalian manajemen dalam suatu perusahaan upaya untuk melakukan evaluasi pada kegiatan yang telah dilakukan dalam perusahaan. Penelitian bertujuan agar mengetahui dan menganalisis pengaruh akuntansi pertanggungjawaban terhadap pengendalian manajemen yang dilakukan oleh PT. Haganamo Mandiri. Penelitian ini menggunakan metode deskriptif. Berdasarkan pengujian yang dilakukan, diketahui bahwa penerapan akuntansi pertanggungjawaban berpengaruh terhadap pengendalian manajemen.
\end{abstract}

Kata Kunci : Akuntansi Pertanggungjawaban, Pengendalian Manajemen.

\begin{abstract}
Accounting is an activity that is very important in identifying, reporting, and providing information to report and assess related parties so that they can take action. Management is a process and ability to regulate an activity as well as control so that the predetermined target is achieved. A good company can implement accounting and management systems according to company needs. Responsibility accounting is very important in all activities that have occurred in the company to interested parties. Management control in a company is an effort to evaluate the activities that have been carried out in the company. This study aims to determine and analyze the effect of responsibility accounting on management control carried out by PT. Haganamo Mandiri. This research uses a descriptive method. Based on the tests conducted, it is known that the application of responsibility accounting has an effect on management control.

Keywords: Accountability Accounting, Management Control.
\end{abstract}

\section{Pendahuluan}

Berkembangnya suatu perusahaan karena produk dan jasa diterima oleh masyarakat, tapi disisi lain akan berkembang pula masalahan yang akan dihadapi suatu perusahaan. Seorang pemimpin perusahaan mengalami kendala untuk mengawasi semua kegiatan yang ada pada perusahaan secara langsung. Walaupun demikian seorang pemimpin perusahaan tetap harus dapat mengetahui masalah yang ada dalam suatu perusahaan. jika mengetahui ada masalah maka segera bertindak mencari sumber penyebab masalah dan akan mencari solusinya sehingga perusahaan tidak mengalami kerugian yang besar. cara yang sering pemimpin gunakan adalah dengan membagi tugas dan tanggungjawab setiap departemen dalam perusahaan. sehingga ada yang bertanggung jawab kepada 
manajer untuk perencanaan dan pemanfaatan sumber daya yang ada seperti akuntansi pertanggungjawaban dan sistem pengendalian manajemen.

Menurut Cikiana, W. (2018), mengatakan bahwa akuntansi pertanggungjawaban merupakan alat ukur pencapaian kegiatan yang telah ditentukan sehingga dapat dipertanggungjawabkan kepada atasan. Sedangkan menurut Nugraha, D. M. A., Nusantoro, J., \& Zanaria, Y. (2021) pengendalian manajemen merupakan suatu strategi untuk mempengaruhi kegiatan dalam perusahaan sehingga mendapatkan hasil yang maksimal sesuai dengan perencanaan awal. Berdasarkan kegiatan dan usaha dapat dikelola dengan baik dan berkesinambungan agar menghasilkan laba secara maksimal, juga bisa memenuhi permintaan pasar.

\subsection{Akuntansi Pertanggungjawaban}

\section{Landasan Teori}

Akuntansi pertanggungjawaban adalah bagian dari akuntansi yang dapat menguraikan dari perencanaan hingga pada pelaporan pencapaian pada periode tertentu akan dipertanggungjawabkan kepada pihak yang berkepentingan. ancangan ini mendasarkan pada atensi dalam penyajian fakta sebagai keperluan internal sebuah perusahaan sekalian membandingkan kinerja manajer dan seluruh stakeholder yang berperan dalam aktivitas perusahaan. Timbul tanggung jawab karena pemberian kekuasaan kepada orang lain dan memiliki kewajiban buat melaksanakan serangkaian tindakan sinkron menggunakan batas kewenangan yg diberikan, lalu mempertanggungjawabkan pada atasan yg menaruh kewenangan. Akuntansi pertanggungjawaban merupakan metode akuntansi dengan begitu teratur sebagai akibatnya pelaporan baik pengeluaran begitu juga pemasukan, sementara target pencapaian dalam suatu periodik dapat diuraikan dengan baik, sehingga informasi yang didapat bagi orang berkepentingang sangat jelas (Abdullah, R. 2018:02). Akuntansi pertanggungjawaban, berita dengan didapatkan sebuah informasi dari yang telah diselesaikan kegiatan dengan membandingkan perencanaan awal sehingga suatu perusahaan dapat berkembang (Wilmar, C. D., Pangemanan, S. S., \& Tirayoh, V. Z, 2019:1042).

Menurut peneliti, Akuntansi pertanggungjawaban merupakan tolak ukur suatu kegiatan baik perencanaan maupun yang telah terlaksanakan bagi pemangku tanggung jawab sehingga bisa membandingkan pencapaian pada kegiatankegiatan sebelumnya, seorang pemimpin mudah untuk mengontrol jalannya suatu kegiatan pada perusahaan jika informasi yang didapat sangat akurat, sementara perusahaan berkembasng pesat dan mendapatkan laba yang maksimal.

\subsection{Pengendalian Manajemen}

Pengendalian manajemen merupakan upaya suatu perusahaan dengan melakukan evaluasi pada kegiatan yang telah dilakukan dalam perusahaan, agar mengetahui pencapaian pada waktu tertentu dengan melakukan perbandingan atas rencana awal perusahaan dengan mengoreksi setiap perbedaan dari rencana awal.

Pengendalian manajemen terjadi prosedur pengaruh rangkap dengan bergantung pada kerja sama buat menciptakan komunikasi antara atasan dengan bawahannya sehingga terjadi peningkatan dalam suatu perusahaan, (Muhammad, N., \& Dabella, Y. 2021:12). Menurut Suyono, E. (2018)," pengendalian manajemen 
adalah elemen menurut akuntansi manajemen dengan memaparkan dan menampung informasi baik secara langsung maupun tidak langsung dengan berkaitan dengan kegiatan perusahaan dengan tujuan kelancaran operasional dalam perusahaan". Peneliti mengemukakan dimana Pengendalian manajemen adalah bagian aktivitas yang melibatkan beberapa pihak pada perusahaan yang turut aktif melakukan dan menjalankan aktifitas mengendalikan suatu perusahaan menggunakan kapabilitasnya yang dimiliki

\subsection{Kerangka Pemikiran}

Peneliti memberikan kerangka pemikiran dalam hal ini Penelitian dilakukan untuk menganalisa Akuntansi Pertanggungjawaban terhadap Pengendalian Manajemen secara kuantitatif, apakah Akuntansi Pertanggungjawaban berpengaruh terhadap Pengendalian Manajemen atau sebaliknya, dapat dilihat pada gambar 2.1 dibawah ini:

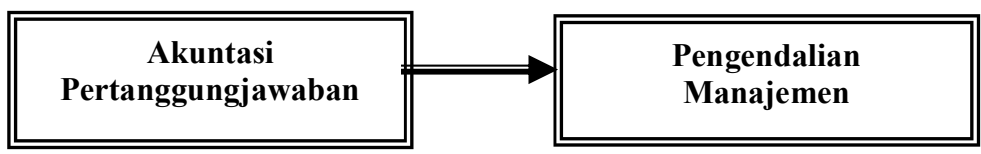

Gambar 1. Kerangka Pemikiran

\subsection{Hipotesis}

Hipotesis adalah pernyataan tentang suatu yang diuji kebenarannya. Terdapat interaksi antara teori terhadap hipotesis yaitu bahwa hipotesis adalah penerangan yang bersifat ad interim namun wajib berdasarkan pada sistematika berdasarkan teori. yang menjadi hipotesis dalam penelitian ini adalah terdapat dampak positif antara variabel Akuntansi Pertanggungjawaban terhadap Pengendalian Manajemen Pada PT. Haganamo Mandiri

\section{METODOLOGI PENELITIAN}

Menurut Anggito, A., \& Setiawan, J. (2018:08) dalam bukunya mengatakan bahwa Penelitian kualitatif merupakan akumulasi data dengan menafsirkan kenyataan yang terjadi peneliti dalam hal ini merupakan instrumen keberhasilan, analisis data dengan kualitatif dan output penelitiannya menekankan profit dibandingkan dengan penyamarataan. berdasarkan pengertian diatas maka, penelitian dengan menggunakan metode deskriptif yang mana data kualitatif akan di analisis pada pengaruh akuntansi pertanggungjawaban terhadap pengendalian manajemen pada PT. Haganamo Mandiri.

\section{1. Uji Kualitas Data}

\section{HASIL PENELITIAN DAN PEMBAHASAN}

a. Uji Validitas

Untuk mengetahui kualitas data maka, peneliti menggunakan metode Pearson Product Moment.

uji validitas pada akuntansi pertanggungjawaban terhadap pengendalian manajemen dapat dilihat sebagai berikut: 
Tabel 1. Akuntansi Pertanggungjawaban

\begin{tabular}{|c|c|c|c|c|}
\hline Item & $\mathrm{N}$ & $\mathrm{R}_{\text {hitung }}$ & $\mathrm{R}_{\text {tabel }}$ & Sig \\
\hline 1 & 30 &, 541 &, 361 &, 002 \\
\hline 2 & 30 &, 484 &, 361 &, 007 \\
\hline 3 & 30 &, 428 &, 361 &, 019 \\
\hline 4 & 30 &, 632 &, 361 &, 000 \\
\hline 5 & 30 &, 412 &, 361 &, 024 \\
\hline 6 & 30 &, 405 &, 361 &, 028 \\
\hline 7 & 30 &, 500 &, 361 &, 005 \\
\hline 8 & 30 &, 416 &, 361 &, 023 \\
\hline 9 & 30 &, 638 &, 361 &, 000 \\
\hline 10 & 30 &, 585 &, 361 &, 001 \\
\hline 11 & 30 &, 413 &, 361 &, 024 \\
\hline 12 & 30 &, 508 &, 361 &, 004 \\
\hline 13 & 30 &, 658 &, 361 &, 000 \\
\hline 14 & 30 &, 422 &, 361 &, 021 \\
\hline 15 & 30 &, 382 &, 361 &, 038 \\
\hline 16 & 30 &, 425 &, 361 &, 019 \\
\hline 17 & 30 &, 593 &, 361 &, 001 \\
\hline 18 & 30 &, 568 &, 361 &, 001 \\
\hline 19 & 30 &, 477 &, 361 &, 008 \\
\hline 20 & 30 &, 414 &, 361 &, 024 \\
\hline 21 & 30 &, 466 &, 361 &, 010 \\
\hline 22 & 30 &, 402 &, 361 &, 028 \\
\hline 23 & 30 &, 456 &, 361 &, 012 \\
\hline 24 & 30 &, 387 &, 361 &, 036 \\
\hline & & & & \\
\hline
\end{tabular}

Berdasarkan uji data ditas, mendapatkan nilai $\mathrm{r}_{\text {hitung }}$ minimum 0,381 sedangkan nilai maksimum 0,658 , sementara nilai $r_{\text {tabel }} 5 \%$ mendapatkan 0,361 , jadi $r_{\text {hitung }}$ lebih besar dari nilai $r_{\text {tabel }}$ sehingga dapat dikatakan diterima semua pertanyaan.

Tabel 2. Pengendalian manajemen

\begin{tabular}{|c|c|c|c|c|}
\hline Item & $\mathrm{N}$ & $\mathrm{R}_{\text {hitung }}$ & $\mathrm{r}_{\text {tabel }}$ & Sig. \\
\hline 1 & 30 &, 685 &, 361 & 0,000 \\
\hline 2 & 30 &, 746 &, 361 & 0,000 \\
\hline 3 & 30 &, 735 &, 361 & 0,000 \\
\hline 4 & 30 &, 826 &, 361 & 0,000 \\
\hline 5 & 30 &, 615 &, 361 & 0,000 \\
\hline 6 & 30 &, 751 &, 361 & 0,000 \\
\hline 7 & 30 &, 667 &, 361 & 0,000 \\
\hline 8 & 30 &, 715 &, 361 & 0,000 \\
\hline 9 & 30 &, 666 &, 361 & 0,000 \\
\hline
\end{tabular}


Berdasarkan uji data ditas, mendapatkan nilai $\mathrm{r}_{\text {hitung }}$ minimum 0,616 sedangkan nilai maksimum 0,826 , sementara nilai $\mathrm{r}_{\text {tabel }} 5 \%$ mendapatkan 0,361 , jadi $\mathrm{r}_{\text {hitung }}$ lebih besar dari nilai $r_{\text {tabel }}$ sehingga dapat dikatakan diterima semua pertanyaan.

b. Uji Reliabilitas

Hasil pengujian reliabilitas menggunakan metode $\mathrm{Alfa}$-Cronbach pada akuntansi pertanggungjawaban terhadap pengendalian manajemen dapat dilihat sebagai berikut:

Tabel 3. Uji Reliabilitas

\begin{tabular}{|l|c|c|}
\hline \multicolumn{1}{|c|}{ Variable } & Alfa-Cronbach & Ket. \\
\hline Akuntansi Pertanggungjawaban &, 732 & Valid \\
\hline Pengendalian manajemen &, 772 & valid \\
\hline
\end{tabular}

Hasil uji reliabilitas menunjukan bahwa Alfa-Cronbach pada akuntansi pertanggungjawaban mendapatkan nilai dengan 0,732 sementara pada pengendalian manajemen mendapatkan nilai dengan 0,772. Sehingga AlfaCronbach akuntansi pertanggungjawaban dan pengendalian manajemen $>0,6$.

c. Uji Normalitas

Hasil uji normalitas menggunakan metode Kolmogorov-Smirnov pada akuntansi pertanggungjawaban terhadap pengendalian manajemen dapat dilihat sebagai berikut:

Tabel 4. Uji Normalitas One-sample Kolmogorov-smirnov tes

\begin{tabular}{|c|c|c|c|}
\hline & & $\mathbf{X}$ & $\mathbf{Y}$ \\
\hline \multicolumn{2}{|l|}{$N$} & 30 & 30 \\
\hline Normal & Mean & 95,43 & 33,70 \\
\hline$\underset{a, b}{\text { Parameters }}$ & Std. Deviation & 7,573 & 4,956 \\
\hline Most & Absolute & 0,177 & $\mathbf{0 , 1 7 7}$ \\
\hline Extreme & Positive & 0,119 & 0,121 \\
\hline Differences & Negative & $-0,177$ & $-0,177$ \\
\hline \multicolumn{2}{|c|}{ Kolmogorov-Smirnov Z } & 0,970 & 0,970 \\
\hline \multicolumn{2}{|c|}{ Asymp. Sig. (2-tailed) } & 0,304 & 0,303 \\
\hline
\end{tabular}

a. Test distribution is normal

b. Calculated from data

Berdasarkan uji data diatas maka, akuntansi pertanggungjawaban mendapatkan nilai 0,304 sedangkan pengendalian manajemen mendapatkan nilai 0,303> $\alpha$ $(0,05)$. Sehingga data penelitian dapat dikatakan valid. 


\section{2. Uji Hipotesis}

a. Analisis Regresi Sederhana

Untuk mengetahui hasil dari analisis regresi sederhana dapat dilihat sebagai berikut:

Tabel 5. Analisis Regresi Sederhana

\begin{tabular}{|c|c|c|c|c|c|}
\hline $\mathrm{X}$ & $\begin{array}{c}\text { Nilai } \\
\text { Regresi }\end{array}$ & \multicolumn{2}{|c|}{$\begin{array}{c}\text { Penyajian Hipotesis } \\
\mathrm{t}_{\text {hitung }}\end{array}$} & $\mathrm{T}$ & Sign \\
\hline $\begin{array}{c}\text { Akuntansi } \\
\text { pertanggungjawaban }\end{array}$ & 0,295 & 2,674 & 2,047 & 0,451 & 0,012 \\
\hline $\mathrm{R}$ & $=0,451$ & \multicolumn{3}{|c|}{${ }^{\mathrm{F}}$ ratio } & $=7,149$ \\
\hline $\mathrm{R}^{2}$ & $=0,203$ & \multicolumn{3}{|c|}{ Signifikansi } & $=0,012$ \\
\hline $\mathrm{Adj}^{2}$ & 0,175 & \multicolumn{3}{|c|}{ Konstanta } & $-5,534$ \\
\hline
\end{tabular}

Persamaan regresi didapat dengan analisis regresi sederhana sehingga mendapatkan persamaan regresi yaitu:

$$
y=5.534+0.295 x
$$

Persamaan regresi yang dapat diinterpretasikan sebagai berikut :

a. Berdasarkan analisis regresi sederhana akuntansi pertanggungjawaban mendapatkan nilai Konstanta sebesar 5,534 sehingga konstanta pengendalian manajemen juga sebesar 5,534.

b. Berdasarkan analisis regresi sederhana akuntansi pertanggungjawaban mendapatkan nilai Koefisien 0,295 artinya ada peningkatan sebesar satuan, maka pengendalian manajemen juga mendapatkan nilai koefisien 0,295 artinya ada peningkatan sebesar satuan. Begitu juga bila terjadi penurunan pada akuntansi pertanggungjawaban menurun maka pengendalian manajemen juga ikut menurun.

b. Koefisien Determinasi atau $\mathrm{R}^{2}$

Koefisien determinasi dengan menggunakan model summary dapat dilihat pada tabel berikut:

Tabel 6. Koefisien Determinasi dengan Model summary

\begin{tabular}{|c|c|c|c|c|}
\hline Model & $R$ & $R$ Square & $\begin{array}{c}\text { Adjusted } R \\
\text { Square }\end{array}$ & $\begin{array}{c}\text { Std. Error of } \\
\text { the Estimate }\end{array}$ \\
\hline 1 & 0,451 & 0,203 & 0,175 & 4.502 \\
\hline
\end{tabular}

a. Predictors, Akuntansi Pertanggungjawaban

Sumber: pengolahan data spss

Berdasarkan koefisien determinasi maka didapat nilai $\mathrm{R}$ sebesar 0,451 artinya akuntansi pertanggungjawaban dengan pengendalian manajemen memiliki hubungan yang sangat kuat karena nilai $\mathrm{R}>0,05$. sedangkan $\mathrm{R}$ square sebesar 0,203 , artinya akuntansi pertanggungjawaban memiliki berpengaruh pada 
pengendalian manajemen sebesar 20,3\%, sementara sebesar 79,7\% dimiliki variabel lain yang tidak diteliti pada penelitian ini.

c. Uji t

Berdasarkan penguraian dan pengujian sebelumnya maka, penelitian memiliki Kriteria sebagai berikut:

a. Jika nilai signifikan lebih besar dari 0,05 , sehingga $\mathrm{H} 0$ diterima sedangkan Ha ditolak. Yang artinya akuntansi pertanggungjawaban dan pengendalian manajemen secara bersama-sama tidak tidak memiliki pengaruh signifikan.

b. Jika nilai signifikansi lebih kecil dari 0,05 sehingga H0 ditolak sedangkan Ha diterima yang artinya akuntansi pertanggungjawaban dan pengendalian manajemen memiliki pengaruh dengan signifikan secara parsial.

c. Penelitian mengharapkan nilai Signifikan sebesar $\alpha=5 \%$

d. Hasil pengujian pada hipotesis dengan bersama-sama maka, akuntansi pertanggungjawaban mendapatkan nilai $t_{\text {hitung }}$ sebesar 2,674 sehingga nilai signifikansi 0,012. Berdasarkan hasil diatas dapat diketahui bahwa $t_{\text {hitung seb }}$ sebesar 2.674 lebih besar dari $t_{\text {tabel }}$ sebesar 2.047. sehingga memiliki tingkat signifikan sebesar 0.05 artinya lebih kecil. Dengan demikian maka dapat dikatakan bahwa akuntansi pertanggungjawaban berpengaruh terhadap Pengendalian manajemen.

\section{KESIMPULAN}

Berdasarkan pengujian menggunakan analisis korelasi dan regresi, Sehingga bisa disimpulkan bahwa akuntansi pertanggungjawaban berpengaruh pada pengendalian manajemen PT. Haganamo Mandiri, karena akuntansi pertanggungjawaban dan pengendalian manajemen memiliki nilai signifikan dengan $t_{\text {hitung }}$ sebesar 2.674 lebih besar dari nila $t_{\text {tabel }}$ sebesar 2.047, dengan nilai signifikan 0.012. Sehingga membuktikan penelitian ini bisa diterima. Selanjutnya akuntansi pertanggungjawaban berpengaruh terhadap pengendalian manajemen sebesar koefisien regresi 5.534 .

\section{DAFTAR PUSTAKA}

Abdullah, R. (2018). Penerapan Akuntansi Pertanggungjawaban Dengan Anggaran Sebagai Alat Pengendalian Biaya (Studi Kasus Pada Cv. Citra Niaga Cemerlang Baubau).

Anggito, A., \& Setiawan, J. (2018). Metodologi penelitian kualitatif. CV Jejak (Jejak Publisher)

Chandra, R. (2017). Penerapan sistem pengendalian manajemen terhadap kinerja keuangan pada PT. Indojaya Agri Nusa. Jurnal Samudra Ekonomi dan Bisnis, 8(1), 619-633.

Cikiana, W. (2018). Analisis Penerapan Akuntansi Pertanggungjawaban sebagai Pengendalian Biaya Pada (UD. Basmalah Jarit Candipuro Lumajang).

Hariyanti, T. (2017). Pengaruh Bauran Pemasaran Terhadap Loyalitas Konsumen Membeli Air Galon Merek Aer Qua Di Kota Pontianak (Doctoral dissertation, FAKULTAS EKONOMI DAN BISNIS). 
MUHAMMAD, N., \& DABELLA, Y. (2021). Model Proses Bisnis ERP, Pengendalian Manajemen dan Keunggulan Kompetitif. JURNAL AKUNTANSI DAN BISNIS, 7(1), 11-22.

Natalya, B., Deviyanti, D. R., \& Kusumawardani, A. (2017). Pengaruh partisipasi anggaran dan akuntansi pertanggungjawaban terhadap kinerja pegawai pada badan pengelola keuangan dan aset daerah kota balikpapan. AKUNTABEL, 13(2), 115-123.

Nugraha, D. M. A., Nusantoro, J., \& Zanaria, Y. (2021). Pengaruh sistem pengendalian manajemen terhadap kinerja perusahaan: Strategi Bisnis dan Inovasi Sebagai Variabel Intervening. Expensive (Jurnal Akuntansi dan Keuangan). 1(1)36-44

Suyono, E. (2018). Pentingnya Sistem Pengendalian Manajemen dalam Pengelolaan Usaha Kecil dan Menengah di Kabupaten Banyumas, Jawa Tengah. Kompartemen: Jurnal Ilmiah Akuntansi, 16(1).

Wilmar, C. D., Pangemanan, S. S., \& Tirayoh, V. Z. (2019). Penerapan Akuntansi Pertanggungjawaban Sebagai Alat Penilaian Kinerja Manajer Pusat Pendapatan Pada PT. Wahana Wirawan Manado-Nissan Datsun Martadinata. Jurnal EMBA: Jurnal Riset Ekonomi, Manajemen, Bisnis dan Akuntansi, 7(1). 